\title{
AN EPISTEMOLOGICAL INQUIRY INTO THE 'WHAT IS LANGUAGE' QUESTION AND THE 'WHAT DID LANGUAGE EVOLVE FOR' QUESTION
}

\author{
NATHALIE GONTIER \\ Research Assistant of the Fund for Scientific Research - Flanders (F.W.O.-Vlaanderen), \\ Centre for Logic and Philosophy of Science, Vrije Universiteit Brussel, Pleinlaan 2, \\ Brussels, 1050, Belgium
}

\begin{abstract}
Although Hauser, Chomsky and Fitch (HCF/FHC) and Pinker and Jackendoff (PJ/JP) differ in the epistemic questions they ask concerning, respectively, the nature of language (what language is), and the evolution of language (what language evolved for), it will be argued that both questions are part of the same methodological framework. This framework resembles the classical manner in which scientific knowledge is to be obtained while newer epistemological methods are suggested that can complement the study of the characteristics of language and evolutionary transitions that led to language.
\end{abstract}

\section{Introduction}

The current debate between, on the one hand, Steven Pinker and Ray Jackendoff (PJ, 2005; JP, 2005) and on the other, Noam Chomsky, Marc Hauser and Tecumseh Fitch (HCF, 2005, FHC, 2005), concerning (amongst other things) the original distinction made by HCF (2002) between the Faculty of Language in the Broad sense (FLB), and the Faculty of Language in the Narrow sense (FLN), is taken as point of departure in order to evaluate the different epistemic frameworks used by these authors.

Methodologically, two different paradigms, each with its own specific epistemic questions, can be distinguished. Proponents of the "language is an adaptation"-paradigm mainly focus on the question of what language evolved for, the most popular answer being, that it evolved for communication (Pinker \& Bloom, 1990; PJ, 2005; JP, 2005). Adherents of the "(aspects of) language is (are) an exaptation"-paradigm basically study what language is, which aspects are uniquely human, and which cognitive domains are unique to/for human language. Here, it will be argued that a large part of the discussion revolves around a failure to acknowledge that each paradigm entails different goals when the what and the what-for-question are asked.

\section{Aristotle and the nature of the scientific enterprise}

In 350 b.C., Aristotle (1970: II 3) stated that to know something is to examine the 4 causes (namely, the material, the formal, the efficient, and the final cause) that underlie that something. These causes can be extracted by asking specific 
questions: to know the true nature or essence of a thing, one needs to ask the what-question (that relates to the material and formal cause). To know how something came into being, one needs to ask the how-question, and to obtain the final goal of something, one needs to ask the what-for-question.

Important for the purpose of this article is the following: Aristotle carefully demonstrated that the what-question and the what-for-question are inextricably related, that is, the essence of a thing, and the final goal of a thing, converge. A human infant, for example, has the potential to grow into an adult member of society, and this is also the final goal of that infant, that its "potential" will

become "actualized". Thus, even before the child is an adult, it has the goal of becoming one. Put differently, Aristotle's world view is a teleological one, namely, essence precedes existence (the goal is already known before it exists).

\section{Which questions are central to functional and evolutionary biology?}

It is general knowledge that with Newton's work, the teleological framework was replaced by a mechanistic one. With the rise of causality-thinking, only the how-question (that relates to Aristotle's efficient cause), that asks about the mechanism, is regarded as scientific. All other questions are rejected.

This is true for all scientific disciplines, except for biology (e.g. Gontier, 2004: 180-195). To investigate which questions are acknowledged as scientific within biology, we need to make a distinction between Neodarwinian theory (that relates to the Modern Synthesis, founded by the population geneticists) and Postneodarwinian theory (the selectionist models that developed after the founding of the Modern Synthesis). In the latter theory, the Modern Synthesis is expanded to include, for example, the "gene's eye view" (Dawkins, 1982).

In 1961, Ernst Mayr, a Neodarwinian, still clearly distinguished between functional biology and evolutionary biology. Functional biologists emphasize the important role that the how-question plays in biology. This in turn, means that the whole is divided into its component parts, and then the question is asked concerning how these parts function individually, and how they function together. When this is known, the whole is known. Mayr (1961: 360):

"The functional biologist is vitally concerned with the operation and interaction of structural elements [...]. His ever-repeated question is 'How?' How does something operate, how does it function? [...H]is approach is essentially the same as that of the physicist and the chemist."

Things get more complicated, when we turn to evolutionary biologists and their inquiry. Here the why-question is still posed. Mayr (1961: 360):

"The evolutionary biologist differs in his method [...] His basic question is Why?'. [...] It may mean 'how come?' but it may also mean the finalistic 'what for?'. It is obvious that the evolutionist has in mind the historical 'how come?' when he asks 'why?'”. 
The why-question, can be interpreted in two different ways (Gontier, 2005); it can be a question that is directed towards the past, or it can be directed towards the future. When the why-question is directed towards the future, this means that why becomes a synonym for the what-for-question, and thus here it relates to the Aristotelian final cause. Thus, when the what-for-question is raised, one does not merely investigate the goal/function/or utility of something, rather one also asks what the essence or true nature of that something is. This is the case, because ever since Aristotle, the what-for and the what-question are intertwined, and both questions together lead to a teleological approach.

Mayr, however, stresses that within biology, there is no place for the whatfor-question. The why-question, can also be directed towards the past, and here it is equated with the how-question, namely how certain characteristics especially adaptive characteristics- emerge historically in evolution of life. Hence, with Mayr, the how-question is elaborated upon to include not only the functioning of the component parts, but also the historical origin of certain traits.

Postneodarwinians, on the contrary, defend a wholely different viewpoint. We take Richard Dawkins' work as an example. The difference with Mayr is that Dawkins defends a position in which the methodology used by functional and evolutionary biologists is the same. Dawkins (2000: 17):

“... what kind of explanation for complicated things would satisfy us. We have just considered the question from the point of view of mechanism: how does it work? [...] But another kind of question is how the complicated things came into existence in the first place. [...] the same general principle applies as for understanding mechanism."

Even more so, contrary to Mayr, Dawkins re-introduces the what-forquestion, directed towards the future:

"The theory of natural selection provides a mechanistic, causal account of how living things came to look as if they had been designed for a purpose. So overwhelming is the appearance of purposeful design that, [...] we still find it difficult indeed boringly pedantic, to refrain from teleological language when discussing adaptation. Bird's wings are obviously 'for' flying, [...]." (Dawkins, 1982: 161, emphasis added)

Just like Mayr, the importance of the how-question is emphasized by Dawkins, in order to, on the one hand, investigate the mechanical functioning of a certain trait, and on the other hand, to investigate the historical, evolutionary origin of certain characteristics. The difference between the two biologists arises when Dawkins stresses that questions concerning the historical and evolutionary origin also require a functional approach.

To be sure, Dawkins (e.g. 2000: 6-7) repeatedly emphasizes that natural selection does not work in a goal-oriented or teleological manner, and thus that the use of the what-for-question is not justifiable. However, he does not succeed in over-bridging a certain ambiguity that surfaces in his writings, concerning the 
use of the what-for-question, an ambiguity that, as we shall discuss under 4.2., especially re-appears in the implementation of his theories by PJ. For now, it suffices to say that in Dawkins' work, the what-for-question remains posed together with the how-question.

\section{How are these paradigms put to use in language (origin) studies ?}

\subsection{The Chomskyan tradition and the essentialist "what is language"- question}

Chomsky's theory of generative grammar explains language as an innate human capacity, that forms an organ in the brain. The young Chomsky's main goal was to criticize behaviourism, an approach that preferred to investigate the external behaviour an organism displays. Chomsky, on the other hand, emphasized that language needs to be studied as an internal component of the brain, also called Ilanguage.

"The shift in locus was from the study of E-language to the study of Ilanguage, from the study of language regarded as an externalized object to the study of the system of knowledge of language attained and internally represented in the mind/brain. [...] UG is a characterization of these innate, biologically determined principles, which constitute $[\ldots]$ the language faculty." Chomsky (1986: 24)

Although language needs to be studied from within biology -as the "biolinguistics"-discipline dictates, this does not immediately or even necessarily imply that the human language faculty also needs to be studied from within evolutionary biology. On the contrary, in his earlier writings, Chomsky emphasizes that the LAD is uniquely human, and that a survey into the evolutionary origin of the LAD from within a comparative evolutionary framework would thus be meaningless. Chomsky argued that evolution had been saltational, leading to a qualitative difference, which excluded an explanation of the origin of the LAD by means of natural selection that follows a gradual pace.

The (Aristotelian) quintessential of language, that what makes language what it is, is the universal grammar, and this aspect becomes the principal focus, the central topic of investigation, in contrast to being concerned with how this faculty evolved. "Hence, the logically prior task of elucidating precisely what evolved has taken research priority over elucidating how it evolved." (Newmeyer, 2003: 60).

In other words, within this tradition, the what-is-language-question is posed as the most important question. In 2002, HCF (2002: 1569-71) specified even more what is uniquely human and what is thus essential to the human language faculty, by making a distinction between the FLB and the FLN. FLB encompasses the sensory-motor system, the conceptual-intentional system and the computational mechanisms required for recursion, while the FLN only 
encompasses recursion. It is the FLN that is defined as uniquely human and thus as that what human language is. It is assumed that most (if not all) other elements of the FLB are shared with other animals and that, although perhaps necessary for language, they are not sufficient to cause human language on the one hand, or to define human language, on the other. Moreover, what is shared with other animals, is not a priori understood to have evolved in the course of evolution for human language (rather, an exaptationist explanation is preferred).

Hence, here we find that, contrary to earlier works of Chomsky, a comparative approach is pursued, albeit in a via negativa way:

"[...] a basic and logically inelimenable role for comparative research on language evolution is this simple and essentially negative one: A trait present in nonhuman animals did not evolve specifically for human language, although it may be part of the language faculty and play an intimate role in language processing." (HCF, 2002: 1572)

Basically, within this paradigm, the comparative method seems to be useful only in so far that it distinguishes the unique properties of human language from those properties that we share with other animals, and hence to answer the "what is unique to human language-question", the answer being "recursion". Thus within this framework, it is assumed that it is possible to distinguish essential properties from accidental ones, the latter being necessary but not sufficient to produce human language or to explain the evolution of human language (not that recursion is either). This last point is rather important, and is, I think, overlooked in the recent criticism given by JP (2005) and PJ (2005). Namely that once we know what language is, what makes human language unique (i.e. recursion), we really do not know anything about the evolution of language, because according to HCF (2002) recursion did not cause the evolution of language, and language did not evolve for recursion, or in order to have recursion. Language just has recursion. Within HCF's theory, "recursion" merely is the answer one needs to give when it is asked what language is, not what language evolved for.

\subsection{The Postneodarwinist tradition and the "what did language evolve for"-question}

In this section, we turn to the Postneodarwinians, and here, too, as we shall see, the how-question becomes of secondary importance, this time because of the emphasis that is given to the "what did language evolve for"-question.

Although bio-linguistics, instructionist models and Neodarwinian models already flourished well before Pinker and Bloom's 1990 article, it was these latter authors who for the first time clearly introduced a selectionist account on the origin of language from within a Postneodarwinian tradition.

Their primary goal was to accomplish a synthesis between Chomsky's theories on the human language faculty and selectionist accounts, by stressing that natural selection can lead, gradually, to the evolution of such an adaptively 
complex device. Inspired by Dawkins (1982, 2000), Pinker and Bloom (1990) state that language shows design, and that, therefore, language is a result of natural selection, because only language can explain such "complex design".

"[...] natural selection remains the only evolutionary force capable of generating complex design, in which a feature of an organism (such as the eye or heart) has a non-random organization that enables it to attain an improbable goal that fosters survival and reproduction [...] (Pinker, 2003: 24).

Natural selection has positively selected for a module in the brain that carries the rules for universal grammar, and this adaptive trait is genetically underpinned (the FOXP2 gene being just one example), hence natural selection can gradually go about its business (Pinker 2003).

Again following Dawkins, in evolutionary language research, too, the whatfor-question is introduced. A partly physical character such as language (physical because it is related to brain structures or certain sets of genes, etc.) can only show "design" if it was selected for a certain function, and that function needs to be beneficial for the carrier in the struggle for existence. Thus, the primary question within selectionist frameworks becomes: what did language evolve for, to what end? Assuming that language is an adaptation, what is the evolutionary benefit that language gives to its carriers, so that it can be selected?

Within selectionist approaches, numerous answers have already been given, the most prominent are that language evolved for communicative and/or social reasons, an explanation also provided by PJ (2005: 223): “... the language faculty evolved gradually in response to the adaptive value of more precise and efficient communication in a knowledge-using, socially interdependent lifestyle." Language was selected for the adaptive advantages that the lexicon and the grammar (distinguishable in syntax, morphology and phonology) provide, because these elements form the design of language (Pinker, 2003).

\subsection{Adaptation or exaptation}

Dividing the FLB into its 3 different subsystems, HCF (2002: 1573) also raises the question of whether these different subsystems, each on its own, underwent a different evolution. If so, the possibility arises that each subsystem once fulfilled functions other than the ones it now performs in today's human language apparatus. If we explore this direction further, acknowledging that the subsystems did fulfil other functions, then we also need to take into account that these functions evolved for other reasons, and also were selected for reasons other than language, in the course of evolution. And this in turn means that language (FLB and/or FLN) is neither necessarily an adaptation, nor that language got selected for the enhancement of communication as PJ propose. According to HCF (2002), especially recursion can turn out to be the result of an exaptation, rather than an adaptation. 
The difference between an adaptation and an exaptation was first introduced by Gould and Vrba in 1982. "A feature is an adaptation only if it was built by natural selection for the function it now performs." (Gould and Vrba, 1998: 53). Postneodarwinians assume that an adaptation involves the selection of a function, more specifically the function that it currently performs. According to PJ, the function of language is communication and this means that language can only be an adaptation if it actually was selected for its communicative possibilities (possibilities that need to be genetically based in order for natural selection to be able to do its work).

An exaptation can take on two different forms (Gould and Vrba 1998: 5455): on the one hand, an adaptation can lose its current function and can obtain a different function, and this new function in turn can become the target of positive selection. On the other hand, exaptation can mean a trait, that never really had a function or that never really was an adaptation, can gain a function and become the target of positive selection. According to HCF, a large part of the FLB and also recursion evolved in an exaptationist manner.

\section{Can we overcome traditional thinking concerning the nature and evolution of language?}

Basically, there are thus two classic questions asked in current language origin studies. Within the Chomskyan tradition, there is a primacy of the what-question, which is mainly posed in order to obtain a proper definition of human language, and this in turn is obtained by looking for the difference between animal communication systems and human language. Within the PJ-tradition, there is a primacy of the "what did language evolve for" question, one possibility being communication in a knowledge-using socially based community. However, in neither of these traditions does the question of how language actually did emerge, receive the prior status that is should receive. The recent HCF-PJ discussion shows that this is the case because both traditions assume that how language evolved will be derived, either from the what language is, or from the what language evolved for question. That is why misunderstandings between the two traditions occur.

I have shown show that, beginning with Aristotle, both the what- and the what-for-question have been intertwined. Indeed, this is one of the major reasons $\mathrm{HCF}$ and PJ end up clashing with each other. But the most important question in research regarding the origin of language should be the how-question, which is the one we have discussed with the use of Ernst Mayr's work. This howquestion, should be (re-)directed towards the past, not towards the future (because it is here that the what-for-question emerges). As such, this question should be integrated directly into language origin studies. 


\section{Acknowledgements}

Sincere thanks to the FWO-Vlaanderen, the R\&D-Department of the VUB, and the CLWF. A warm thanks also goes out to Roslyn Frank.

\section{References}

Aristotle. (1970). Aristotle's Physics. Book I and II. Oxford: Clarendon. Chomsky, N. (1985). Knowledge of Language. Westport: Praeger.

Chomsky, N., Hauser, M. D., \& Fitch, W. T. (2005). Appendix. The minimalist program. Unpublished, available at www.wjh.harvard.edu/ mnkylab.

Dawkins, R. (1982). Replicators and vehicles. In R. Brandon and R. Burian, Eds., Genes, organisms and populations (pp. 161-79). Cambridge MA: MIT.

Dawkins, R. (2000). The Blind Watchmaker. London: Penguin Books.

Fitch, W. T., Hauser, M.D., Chomsky, N. (2005). The evolution of the language faculty: clarifications and implications. Cognition, 79 (2), 179-210.

Gontier, N. (2004). De oorsprong en evolutie van leven: 15 van het standaardparadigma afwijkende thesen. Brussels: Vubpress.

Gontier, N. (2005). Introduction to evolutionary epistemology, language and culture. In N. Gontier, J.P. Van Bendegem and D. Aerts (Eds.), Evolutionary Epistemology, Language and Culture (pp. 1-29). Dordrecht: Springer.

Gould, S. J., \& Vrba, E. S. (1998). Exaptation: a missing term in the science of form. In D. Hull and M. Ruse (Eds.), The philosophy of biology (pp. 52-71). Oxford: Oxford University Press.

Hauser, M., Chomsky, N., \& Fitch, W. (2002). The faculty of language: what is it, who has it, and how did it evolve ? Science, 298, 1569-1580.

Jackendoff, R., \& Pinker, S. (2005). The nature of the language faculty and its implications for evolution of language (Reply to Fitch, Hauser, and Chomsky). Cognition, 97 (2), 211-225.

Mayr, E. (1961). Cause and effect in biology. In E. Mayr (ed.), (1997), Evolution and the diversity of life (pp. 359-382). Harvard: Harvard University Press.

Newmayer, F. (2003). What can the field of linguistics tell us about the origin of language? In M. H. Christiansen and S. Kirby (Eds.), Language evolution (pp. 58-76). Oxford: Oxford University Press.

Pinker, S., (2003). Language as an adaptation to the cognitive niche. In M. H. Christiansen and S. Kirby (Eds.), Language evolution (pp. 16-37). Oxford: Oxford University Press.

Pinker, S., \& Bloom, P. (1990). Natural language and natural selection. Behavioral and Brain Sciences, 13, 707-784.

Pinker, S., \& Jackendoff, R. (2005). The faculty of language: what's special about it? Cognition, 95, 201-236. 